\title{
Can Brain Natriuretic Peptide Be Used as an Indicator of Over-infusion in Patients with Acute Sepsis? : A Pilot Study Evaluating Correlation Between Brain Natriuretic Peptide and Global End- diastolic Volume Index
}

\section{Yuki Kishihara}

Musashino Red Cross Hospital: Musashino Sekijuji Byoin

Hideto Yasuda ( $\nabla$ yasudahideto@me.com )

Jichi Medical University Saitama Medical Center https://orcid.org/0000-0003-3153-1595

Kenichiro Morisawa

Saint Marianna University School of Medicine: Sei Marianna Ika Daigaku

\section{Shigeki Fujitani}

Saint Marianna University School of Medicine: Sei Marianna Ika Daigaku

Yosuke Homma

Tokyo Bay Urayasu Ichikawa Medical Center

Kazuaki Shigemitsu

Osaka City General Hospital: Osaka Shiritsu Sogo Iryo Center

Nobuyuki Saito

Chiba Hokusou Hospital

Katsura Hayakawa

Saitama Red Cross Hospital

Toru Hifumi

Kagawa University Hospital

Hiroshi Rinka

Osaka City General Hospital

\section{Toshihiko Mayumi}

University of Occupational and Environmental Health School of Medicine Graduate School of Medicine:

Sangyo Ika Daigaku Igakubu Daigakuin Igaku Kenkyuka

\section{Shinsuke Fujiwara}

National Hospital Organization Ureshino Medical Center

Yoshinori Murao

Kindai University Hospital

Yasuhiko Taira 


\section{Research}

Keywords: sepsis, fluid resuscitation, over-infusion, BNP, TPTD, GEDI

Posted Date: October 29th, 2020

DOl: https://doi.org/10.21203/rs.3.rs-97831/v1

License: (9) This work is licensed under a Creative Commons Attribution 4.0 International License. Read Full License 


\section{Abstract}

Background: Recently, for patients with sepsis, under-infusion, that hastens the progression to multiple organ failure and death, has been avoided; however, the rate of over-infusion and resulting complications, such as mortality has increased. There are few indicators of over-infusion, such as transpulmonary thermodilution; therefore, minimally invasive, simple, and quick indicators of over-infusion are needed. This pilot study aimed to determine the association between brain natriuretic peptide (BNP) and global end-diastolic volume index (GEDI).

Methods: This was a post-hoc analysis of a multicenter prospective randomized controlled study, performed in the intensive care units (ICU) of 10 separate hospitals in Japan from September 2013 to March 2016. Patients with sepsis who were expected to require mechanical ventilation for more than 48 hours were included. We measured BNP and GEDI every 24 hours from ICU admission until next 72 hours. The primary outcome was the correlation between BNP and GEDI that was assessed in two ways: 1) GEDI considered a continuous variable, and 2) GEDI divided into two groups based on a cutoff of $850 \mathrm{ml} / \mathrm{m}^{2}$, which is the upper limit of normal GEDI. We used a univariable generalized linear mixed-effects model in which patients are considered as a random effect.

Results: Fifty-seven patients were analyzed. GEDI remained under the upper limit of normal GEDI (850 $\mathrm{ml} / \mathrm{m}^{2}$ ) from ICU admission to $72 \mathrm{~h}$, and there were no significant changes in the trends of BNP and GEDI over time. BNP tended to be higher in group 1 (GEDI $>850 \mathrm{ml} / \mathrm{m}^{2}$ ) from ICU admission to $72 \mathrm{~h}$, but there was no significant difference in the BNP values. The regression coefficient and $95 \% \mathrm{Cl}$ of BNP for GEDI were 2.5 and 1.3 to 3.7 when considered as a continuous variable, and 166 and -273 to 605 when divided into two groups based on GEDI cutoff of $850 \mathrm{ml} / \mathrm{m}^{2}$.

Conclusion: There could be a weak but significant correlation between GEDI and BNP considering GEDI as a continuous variable. Using BNP as an indicator of over-infusion may be possible; however, further studies are needed.

Trial registration: None.

\section{Background}

Until recently, sepsis has been one of the most serious diseases, with a mortality rate up to $50 \%{ }^{(1)}$. Since the cause of death in sepsis is the lack of oxygen delivery, and multiple organ failure due to the progression of sepsis, early fluid resuscitation has been considered important to avoid the progression to multiple organ failure and death ${ }^{(2)(3)}$. With the widespread use of the Surviving Sepsis Campaign Guideline (SSCG), a treatment bundle for sepsis that recognized proper fluid resuscitation, an improvement in sepsis-related mortality of approximately $30 \%$ was reported ${ }^{(4)(5)}$. Consequently, fluid resuscitation became established because of robust evidence. However, in an attempt to prevent underinfusion, the rate of over-infusion has increased and there are growing concerns on the complications 
resulting from over-infusion. Currently, complications such as mortality due to over-infusion are being increasingly reported, and it is important to control not only the under-infusion but also the over-infusion of fluids ${ }^{(6)(7)}$.

The usefulness of indicators of infusion, such as pulmonary artery wedge pressure (PAWP), stroke volume variation (SVV), lactic acid, and urine output, has been examined in patients with sepsis; however, these have been mainly useful for monitoring under-infusion, and cannot be effective in monitoring overinfusion $^{(8)(9)(10)}$. Conversely, transpulmonary thermodilution (TPTD) is a medical device that can be used to monitor over-infusion ${ }^{(11)}$. In particular, accumulating evidence suggests that the global end-diastolic volume index (GEDI), which is measured using TPTD and reflects the volume of blood in the end-diastolic heart cavity, can be used as a monitoring index for under-infusion in patients with sepsis ${ }^{(12)(13)}$. However, TPTD may not be always be available due to the complexity of the procedure and the need for specialized devices.

Brain natriuretic peptide (BNP) is a ventricle-derived hormone that is elevated by ventricular load and is widely used in the diagnosis of heart failure ${ }^{(14)}$. In addition BNP can be measured in blood by a minimally invasive procedure. Few studies have reported the dynamics of BNP in diseases other than heart failure. Although the association of BNP with prognosis and prediction of infusion responsiveness has been studied in patients with sepsis, it is not known whether it can be used as an indicator of over-infusion in patients with sepsis ${ }^{(15)(16)(17)(18)}$.

Therefore, in this study, we hypothesized that BNP, could be used as an indicator of over-fluidization in patients with sepsis instead of GEDI. The objective of the current study is to evaluate an association between GEDI and BNP, what will ultimately lead to the understanding whether BNP can be a surrogate for over-infusion assessment.

\section{Methods}

\section{Q Design, patients}

This study was a post-hoc analysis of a multicenter randomized controlled trial which was already published in Acute Medical Surgery on November 22, 2019(19). Patients admitted to the intensive care units (ICU) at 10 centers in Japan between October 2013 and March 2016 were included. The main study was approved by the clinical research ethics review committee of the central institution, St. Marianna University School of Medicine Hospital. This paper adhered to the standards laid down in the Strengthening the Reporting of Observational Studies in Epidemiology (STROBE) Statement ${ }^{(20)}$.

Inclusion criteria of the main study were patients who met 1) the diagnosis of sepsis (meeting the diagnostic criteria for infection and systemic inflammatory response syndrome (SIRS)) and 2) the expected need for mechanical ventilation for more than 48 hours ${ }^{(21)}$. Patients having any of the following conditions that could lead to inaccurate TPTD readings were excluded in the main study: age $<18$ years; 
current pregnancy; burn; drug toxicity; severe pancreatitis; acute phase of stroke; acute coronary syndrome; severe valvular disease; arrhythmia detected at admission; unstable hemodynamic status with extracorporeal membrane oxygenation (ECMO), or intra-aortic balloon pumping (IABP); unsuitable situation for monitoring central venous pressure (CVP), or TPTD; time elapsed $>24 \mathrm{~h}$ prior to eligibility evaluation; a "Do not resuscitate" code status; regular hemodialysis; and attending physician's decision. In addition, patients with any of the following conditions that could also lead to inaccurate TPTD readings were excluded in this study: ischemic heart disease (including medical history); chronic heart failure; cardiomyopathy (including medical history); chronic kidney disease (including maintenance dialysis); BNP not collected; GEDI not collected; consent withdrawal; or duplicate registration.

\section{QData collection}

The extracted items were age, sex, comorbidities, Simplified Acute Physiology Score II (SAPS II), worst systolic blood pressure, maximum noradrenaline dose and total volume of infusion (within $24 \mathrm{~h}$ of ICU admission), BNP, GEDI, lactic acid level, Continuous Central Venous Oxygen Saturation $\left(\mathrm{ScVO}_{2}\right)$ and sequential organ failure assessment (SOFA) score $(0,24,48$, and $72 \mathrm{~h}$ ), and renal replacement therapy (RRT) during ICU admission. We terminated the follow-up after $72 \mathrm{~h}$ of data collection or earlier in case of ICU discharge, transfer, discharge, or death. Information on the extraction factors was not masked because the information was collected by the physicians-in-charge at each center, and furthermore, the outcome assessors were not blinded. Missing data were not completed and patients having missing data were excluded.

\section{口Outcome}

The primary outcomes was an association between the values of the BNP and GEDI.

uStatistical analysis

Continuous variables are expressed as medians and interquartile ranges (IQR) and analyzed using the Mann-Whitney U test; categorical data are expressed as absolute numbers and percentages (\%). The correlation between BNP and GEDI was assessed in two ways: 1) GEDI considered a continuous variable, and 2) GEDI divided into two groups based on a cutoff of $850 \mathrm{ml} / \mathrm{m}^{2}$, which is the upper limit of normal GEDI since we intended to consider an index of over-infusion. Regarding the association between BNP and GEDI and considering the fact that this study used repeated measures data, we used a generalized linear mixed-effects model in which patients are treated as variable effect. In this study, covariates affecting the outcome were considered to be excluded according to the exclusion criteria of the study, and therefore, the outcomes are analyzed via univariate analysis using EZR (Version 1.38), R (3.5.2.tar.gz) and SAS (Version 9.4) ${ }^{(22)(23)}$. We used $p<0.05$ to detect statistically significant differences.

\section{Results}


A total of 372 patients were enrolled and 164 patients were analyzed in the main study. Regarding the reasons for exclusion, 53 patients had arrhythmias at the initial phase, 32 patients did not matched physician's treatment policy, 26 patients failed to provide informed consent, 9 patients had difficulty in CVP or TPTD monitoring, while the other reasons are mentioned in Fig. 1. A total of 164 patients were thus eligible for this study of which 57 patients were included in the analysis. Regarding the reasons for exclusion in this study, 9, 4, and 3 patients had a history of ischemic heart disease, chronic heart failure, and cardiomyopathy, respectively. In addition, 9 patients had a history of chronic kidney disease, while the other reasons are mentioned in Fig. 1. There were 181 BNP measurements and 162 GEDI measurements, and 157 pairs were matched. Finally, data of 57 unique patients were analyzed.

Table 1 shows the baseline characteristics of the analyzed patients. The age of the patients was 73 (5782) years [median (IQR)]. There were 37 male patients (64.9\%) and SAPS II was 53 (46-69); 35 patients had septic shock on ICU admission (61.4\%). The maximum noradrenaline administered within $24 \mathrm{~h}$ of ICU admission was $0.1(0-0.2) \mu \mathrm{g} / \mathrm{ml} / \mathrm{min}$, and the total volume of infusion administered within $24 \mathrm{~h}$ of ICU admission was 4492 (3348-6578) $\mathrm{ml}$. (Table 1$)$

Figure 2 shows the trends of BNP and GEDI during $72 \mathrm{~h}$ from the initiation of resuscitation for sepsis. GEDI remained under the upper limit of normal GEDI $\left(850 \mathrm{ml} / \mathrm{m}^{2}\right)$ from ICU admission over the next $72 \mathrm{~h}$, and there were no apparent changes in the trends of either BNP or GEDI over time (The statistical test was not performed).

GEDI was divided into two parts based on the cutoff of $850 \mathrm{ml} / \mathrm{m}^{2}$, and the changes in BNP according to the time are described in Table 2. Although BNP tended to be higher in group 2 (GEDI> $850 \mathrm{ml} / \mathrm{m}^{2}$ ) from ICU admission to $72 \mathrm{~h}$, this difference was not statistically significant $(p \geqq 0.05)$. (Table 2 )

Using a univariable generalized linear mixed-effects model considering the patients as random effects, the regression coefficients and 95\% Cls of BNP for GEDI were 2.5 and 1.3 to $3.7(p<.001)$, when considered a continuous variable, and 166 and -273 to $605(p=0.46)$, when divided into two 2 groups based on GEDI, with $850 \mathrm{ml} / \mathrm{m}^{2}$ as the cutoff. (Table 3, Fig. 3)

\section{Discussion}

In this study, the BNP and GEDI in patients with sepsis undergoing invasive ventilation were mildly but significantly correlated when GEDI was considered a continuous variable.

GEDI is considered to be a measure of the systemic fluid volume, because GEDI is calculated by dividing the global end-diastolic volume (GEDV) by the body surface area, which indicates the intrathoracic and pulmonary vascular blood volume ${ }^{(11)}$. In contrast, BNP, a hormone synthesized mainly by the ventricles, has been used as a biochemical marker that sensitively reflects the degree of ventricular load, because its secretion is increased by ventricular load, causing a rise in its blood concentration ${ }^{(24)}$. BNP is a superior auxiliary diagnostic method for heart failure, because plasma BNP concentrations correlate well with the 
hemodynamics, and BNP reflects the left ventricular load precisely ${ }^{(25)}$. In this study, GEDI was elevated due to the increased circulating plasma volume in response to the acute phase of sepsis infusion load. Similarly, BNP was also elevated in response to the left ventricle progression in response to the infusion load. These facts could indicate that BNP may be elevated in the acute phase of sepsis as well similar to the pathogenesis of heart failure, reflecting the excess fluid volume in the acute phase of sepsis.

However, the correlation coefficient between BNP and GEDI was 2.5; the value was small and the correlation was mild, which may render it difficult for use in clinical practice. There could be three possible reasons for the small correlation coefficient: first, as shown in Fig. 2, the median values of GEDI in this study over the three days of ICU stay remained within the upper limit of normal $\left(850 \mathrm{ml} / \mathrm{m}^{2}\right)$. Therefore, it could be possible that BNP was not secreted and was thus not sufficiently elevated due to the insufficient increase in blood volume in the left ventricular cavity, and the lack of expansion of the left ventricular cavity associated with the infusion load. The second reason, as noted in the early goaldirected therapy (EGDT), the acute phase of sepsis requiring large amount of volume infusion is generally considered to be approximately 6 hours from the diagnosis of sepsis ${ }^{(26)}$. In this study, the inclusion of data up to 72 hours when volume infusions are no longer needed and GEDI and BNP were no longer elevated, might have resulted in a small correlation coefficient and mild correlation. The third reason: BNP rises within 1 hour of stimulation and has a biological half-life of 20 minutes in the body ${ }^{(17)}$. Since the GEDI and BNP measurements in this study were performed every 6 hours, it is possible that even though the left ventricular cavity was sufficiently enlarged by volume infusion to cause an increase in BNP, the very short half-life of the BNP caused a decrease at the time of measurement, which might have resulted in a small and mild correlation coefficient.

Considering these reasons, it may be possible to obtain larger regression coefficients and stronger correlations by shortening the measurement period of BNP to within 6 hours from starting the treatment and shortening the measurement interval to every hour or so.

Since the present study has revealed a possible association between BNP and GEDI, this study could guide further studies evaluating the usefulness of BNP as an indicator of over-infusion, using the upper limit of GEDI as a cutoff value as the index of over-infusion. Although this study is a pilot study, if further studies show that BNP can be an indicator of over-infusion, a minimally invasive, simple, and quick assessment of over-infusion would be possible. This finding could lead to avoidance of over-fusion, which might lead to a reduction in the adverse events, including increased mortality, and thus might have tremendous clinical benefit.

However, there are several limitations in this study. First, as noted in the EGDT, the acute phase of sepsis in which we need large volume of infusion is generally considered to be approximately 6 hours from the diagnosis of sepsis ${ }^{(26)}$. Because the GEDI and BNP assessments in this study were conducted at 0,24 , 48 , and 72 hours after ICU admission, when volume infusions were no longer needed, and GEDI and BNP were no longer elevated, this might have contributed to a small correlation coefficient and mild correlation. Second, the median SAPS II score was 53 in this study, which is not suggestive of the most 
critically ill patients. In addition, the median infusion volume within 24 hours from ICU admission was $4492 \mathrm{ml}$ and the median GEDI time series were all within the upper limit of normal for GEDI $\left(850 \mathrm{ml} / \mathrm{m}^{2}\right)$. These facts suggest that the patients in this study were not severely ill requiring large amount of infusion; thus, the increase in GEDI and BNP was small, and neither GEDI nor BNP was elevated, and thus, no correlation was found. Third, the half-life of BNP is 20 minutes, and even if BNP was elevated, we could not record an increase in BNP by the 6-hourly measurements. Fourth, due to insufficient number of analyzed patients, we might not be able to detect significant differences when using a generalized linear mixed-effects model with GEDI of $850 \mathrm{ml} / \mathrm{m}^{2}$ as the cutoff for the two groups. Fifth, the results of this study may be biased because the patients with severe anemia or acute kidney injury, in whom errors in BNP and GEDI measurements can occur, were not excluded.

Nevertheless, this pilot study suggests that GEDI and BNP may be correlated when GEDI is considered a continuous variable. However, further studies are warranted to increase the number of patients and obtain more frequent BNP measurements within the first six-hours.

\section{Conclusions}

In conclusion, there could be a weak but significant correlation between GEDI and BNP considering GEDI as a continuous variable. It may be possible to use BNP as an indicator of over-infusion; however, that needs further studies.

\section{List Of Abbreviations}

BNP, brain natriuretic peptide; CVP, central venous pressure; ECMO, extracorporeal membrane oxygenation; EGDT, early goal-directed therapy; GEDI, global end-diastolic volume index; GEDV, global end-diastolic volume; IABP, intra-aortic balloon pumping; ICU, intensive care unit; IQR, inter quartile range; PAWP, pulmonary artery wedge pressure; RRT, renal replacement therapy; SAPS II, simplified acute physiology score II; Scv02, continuous central venous oxygen saturation; SIRS, systemic inflammatory response syndrome; SOFA, sequential organ failure assessment; SSCG, surviving sepsis campaign guideline; SVV, stroke volume variation; TPTD, transpulmonary thermodilution

\section{Declarations}

\section{Acknowledgements}

The authors acknowledge the support of Editage (www.editage.jp) for English language editing.

\section{Authors' contributions}

Design of the study: HY, SF, YH, KS, NS, KH, TH, HR, TM, SF, YM and YT. Manuscript concept and design: YK and HY. Statistical analysis: YK and HY. Drafting and approval of final manuscript: YK and HY. All authors read and approved the final manuscript. 


\section{Funding}

None.

\section{Availability of data and materials}

The data and materials of this study are available from the corresponding author on reasonable request.

\section{Ethics approval and consent to participate}

Not obtained since this was a post-hoc analysis of a published study.

\section{Consent for publication}

Not applicable.

\section{Competing interests}

None.

\section{References}

1. Friedman G, Silva E, Vincent JL. Has the mortality of septic shock changed with time. Crit Care Med 1998;26:2078-86.

2. Rhodes A, Evans LE, Alhazzani W, Levy MM, Antonelli M, Ferrer R, et al. Surviving Sepsis Campaign: international guidelines for management of sepsis and septic shock: 2016. Crit Care Med. 2017;45:486-552.

3. Cecconi M, De Backer D, Antonelli M, Beale R, Bakker J, Hofer C, et al; Task Force of the European Society of Intensive Care Medicine. Consensus on circulatory shock and hemodynamic monitoring. Intensive Care Med. 2014;40:1795-1815.

4. Levy MM, Evans LE, Rhodes A. The Surviving Sepsis Campaign bundle: 2018 update. Crit Care Med. 2018;46:997-1000.

5. Levy MM, Dellinger RP, Townsend SR, Linde-Zwirble WT, Marshall JC, Bion J, et al. The Surviving Sepsis Campaign: Results of an international guideline-based performance improvement program targeting severe sepsis. Intensive Care Med 2010;36:222-31.

6. Boyd JH, Forbes J, Nakada TA, Walley KR, Russel JA. Fluid resuscitation in septic shock: A positive fluid balance and elevated central venous pressure are associated with increased mortality. Crit Care Med 2011;39:259-65.

7. RENAL Replacement Therapy Study Investigators, Bellomo R, Cass A, Cole L, Finfer S, Gallagher M, et al. An observational study fluid balance and patient outcomes in the randomized evaluation of normal vs. augmented level of replacement therapy trial. Crit Care Med 2012;40:1753-60. 
8. Jansen TC, van Bommel J, Schoonderbeek FJ, Visser SJS, van der Clooster JM, Lima AP, et al. Early lactate-guided therapy in intensive care unit patients: a multicenter, open-label, randomized controlled trial. Am J Respir Crit Care Med. 2010;182:752-61.

9. Theerawit $P$, Morasert T, Sutherasan $Y$. Inferior vena cava diameter variation compared with pulse pressure variation as predictors of fluid responsiveness in patients with sepsis. $\mathrm{J}$ Crit Care 2016;36:246-51.

10. Teboul JL, Saugel B, Cecconi M, de Backer D, Hofer CK, Monnet X, et al. Less invasive hemodynamic monitoring in critically ill patients. Intensive Care Med. 2016;42:1350-9.

11. Combes A, Berneau JB, Luyt CE, Trouillet JE. Estimation of left ventricular systolic function by single transpulmonary thermodilution. Intensive Care Med. 2004;30:1377-83.

12. Antal O, Ștefănescu E, Mleșnițe M, Balan AM, Caziuc A, Hagau N. Hemodynamic predictors for sepsis-induced acute kidney injury: A preliminary study. J Clin Med. 2020;9:pii: E151.

13. Yu J, Zheng R, Lin H, Chen Q, Shao J, Wang D. Global end-diastolic volume index vs CVP goaldirected fluid resuscitation for COPD patients with septic shock: a randomized controlled trial. Am J Emerg Med. 2017;35:101-5.

14. Maisel A. B-type natriuretic peptide levels: Diagnostic and prognostic in congestive heart failure: What's next? Circulation. 2002 May 21;105:2328-31.

15. Vallabhajosyula S, Wang Z, Murad MH, Vallabhajosyula S Sundaragiri PR, Kashani K, et al. Natriuretic peptides to predict short-term mortality in patients with sepsis: A systematic review and meta-analysis. Mayo Clin Proc Innov Qual Outcomes. 2020 Jan 8;4:50-64.

16. Bai YL, Hu BL, Wen HC, Zhang YL, Zhu J. Prognostic value of plasma brain natriuretic peptide value for patientswith sepsis: A meta-analysis. J Crit Care. 2018 Dec;48:145-52.

17. Omar S, Ali A, Atiya Y, Mathivha RL, Dulhunty JM, et al. Changes in B-type natriuretic peptide and related hemodynamic parameters following a fluid challenge in critically ill patients with severe sepsis or septic shock. Indian J Crit Care Med. 2017;21:117-21.

18. Sturgess DJ, Pascoe RL, Scalia G, Venkatesh B. A comparison of transcutaneous doppler corrected flow time, b-type natriuretic peptide and central venous pressure as predictors of fluid responsiveness in septic shock: a preliminary evaluation. Anaesth Intensive Care. 2010;38:336-41.

19. Morisawa K, Fujitani S, Homma Y, Shigemitsu K, Saito N, Hayakawa K, et al. Can the global enddiastolic volume index guide fluid management in septic patients? A Multicenter Randomized Controlled Trial. Acute Med Surg. 2019;7:e468.

20. Erik von Elm, Douglas G Altman, Matthias Egger, et al. The Strengthening the Reporting of Observational Studies in Epidemiology (STROBE) Statement: guidelines for reporting observational studies. Int J Surg. 2014 Dec;12(12):1495-9.

21. Bone RC, Fisher CJ Jr, Clemmer TP, Slotman GJ, Metz CA, Balk RA. Sepsis syndrome: a valid clinical entity. Methylprednisolone Severe Sepsis Study Group. Crit Care Med 1989;17:389-93.

22. Kanda Y. Investigation of the freely-available easy-to-use software "EZR" (Easy R) for medical statistics. Bone Marrow Transplant. 2013;48:452-8. 
23. R Core Team (2018). R: A language and environment for statistical computing. R Foundation for Statistical Computing, Vienna, Austria. Available online at https://www.R-project.org/.

24. K Nakao, Y Ogawa, S Suga, Imura H. Molecular biology and biochemistry of the natriuretic peptide system. I: Natriuretic peptides. J Hypertens. 1992;10:907-12.

25. Yamamoto K, Burnett JC Jr, Jougasaki M, Nishimura RA, Bailey KR, Saito Y, et al. Superiority of brain natriuretic peptide as a hormonal marker of ventricular systolic and diastolic dysfunction and ventricular hypertrophy. Hypertension. 1996;28:988-94.

26. Rivers E, Nguyen B, Havstad S, Ressler J, Muzzin A, Knoblich B, et al. Early goal-directed therapy in the treatment of severe sepsis and septic shock. N Engl J Med. 2001;345:1368-77.

\section{Tables}

Table 1

Baseline characteristics of all analyzed patients.

\begin{tabular}{|c|c|}
\hline Variables & Patients $(n=57)$ \\
\hline Age, year [median value (IQR)] & $73(57-82)$ \\
\hline Male, No. (\%) & $37(64.9)$ \\
\hline Charlson comorbidity index [median value (IQR)] & $1(0-2)$ \\
\hline Systolic blood pressure*, mmHg [median value (IQR)] & $98(81-120)$ \\
\hline SOFA score $^{\star \star}[$ median value (IQR)] & $12(9-14)$ \\
\hline SAPS $\triangle$ [median value (IQR)] & $53(46-69)$ \\
\hline Septic shock**, No. (\%) & $35(61.4)$ \\
\hline $\mathrm{ScvO}_{2}{ }^{* *}, \%$ [median value (IQR)] & $70(64-78)$ \\
\hline Lactic acid**, mmol/dl [median value (IQR)] & $2.2(1.4-4.1)$ \\
\hline Maximum noradrenaline in 24 hours, $\mu \mathrm{g} / \mathrm{ml} / \mathrm{min}$ [median value (IQR)] & $0.1(0-0.2)$ \\
\hline Total volume of infusion in 24 hours, $\mathrm{ml}$ [median value (IQR)] & $4492(3348-6578)$ \\
\hline RRT during ICU stay, No. (\%) & $11(19.3)$ \\
\hline \multicolumn{2}{|c|}{$\begin{array}{l}\text { Abbreviations: ICU, intensive care unit; IQR, interquartile range; RRT, renal replacement therapy; SAPS, } \\
\text { simplified acute physiology score; ScVO2, continuous central venous oxygen saturation; SOFA, } \\
\text { sequential organ failure assessment. }\end{array}$} \\
\hline \multicolumn{2}{|l|}{ *The worst value from ICU admission to $24 \mathrm{hr}$. } \\
\hline${ }^{\star *}$ These variables were collected on ICU admission. & \\
\hline
\end{tabular}


Table 2

Values of BNP in the order of time scales, grouped by GEDI.

\begin{tabular}{|llll|}
\hline & $\begin{array}{l}\text { Group 1 } \\
\left(\text { GEDI } \leqq 850 ~ m l / m^{2}\right)\end{array}$ & $\begin{array}{l}\text { Group 2 } \\
(\text { GEDI > 850 ml/m²) }\end{array}$ & p value \\
\hline $0 \mathrm{~h}$ & $233(91.6-473)$ & $596(129-1260)$ & 0.32 \\
\hline $24 \mathrm{~h}$ & $124(64.7-524)$ & $302(61.9-459)$ & 0.95 \\
\hline $48 \mathrm{~h}$ & $230(90-635)$ & $190(101-325)$ & 0.85 \\
\hline $72 \mathrm{~h}$ & $175(114-470)$ & $324(134-1430)$ & 0.34 \\
\hline All times & $198(81-530)$ & $276(96-782)$ & 0.46 \\
\hline Abbreviations: BNP, brain natriuretic peptide; GEDI, global end diastolic volume.
\end{tabular}

Table 3

The correlation between BNP and GEDI.

\begin{tabular}{|lllll|}
\hline Nature of GEDI & $\begin{array}{l}\text { regression } \\
\text { coefficient }\end{array}$ & $\begin{array}{l}95 \% \mathrm{Cl} \\
\text { (lower) }\end{array}$ & $\begin{array}{l}95 \% \mathrm{Cl} \\
\text { (upper) }\end{array}$ & $\begin{array}{l}\text { p } \\
\text { value }\end{array}$ \\
\hline $\begin{array}{l}\text { GEDI considered a continuous } \\
\text { variable }\end{array}$ & 2.5 & 1.3 & 3.7 & 0.46 \\
\hline $\begin{array}{l}\text { GEDI considered as categorical } \\
\text { data } \\
\text { (cutoff value: } 850 \mathrm{ml} / \mathrm{m}^{2} \text { ) }\end{array}$ & 166 & -273 & 605 & \\
\hline $\begin{array}{l}\text { The correlations were assessed in two ways: } 1 \text { ) GEDI was considered a continuous variable, and 2) } \\
\text { GEDI was divided into two groups based on a cutoff of 850 ml/m², which is the upper limit of normal } \\
\text { GEDI, as we want to assess an index of over-infusion. We used a generalized linear mixed effects } \\
\text { model in which patients are treated as a variable effect. Abbreviations: BNP, brain natriuretic peptide; } \\
\text { Cl, confidence interval; GEDI, global end diastolic volume. }\end{array}$ & \\
\hline
\end{tabular}

\section{Figures}


Excluded patients in the main study $(n=208)$

Arrhythmia at the initial phase $(n=53)$

Physician's policy $(n=32)$

Failure to obtain informed consent $(n=26)$

Difficulty for CVP or TPTD monitoring $(n=9)$

Regular dialysis $(n=18)$

DNAR order $(n=17)$

$>24 \mathrm{~h}$ from eligibility $(n=12)$

$\operatorname{ECMO}(n=11)$

Stroke $(n=6)$

Drug toxicity $(n=5)$

Coronary disease $(n=5)$

Burn $(n=2)$

Severe pancreatitis $(n=1)$

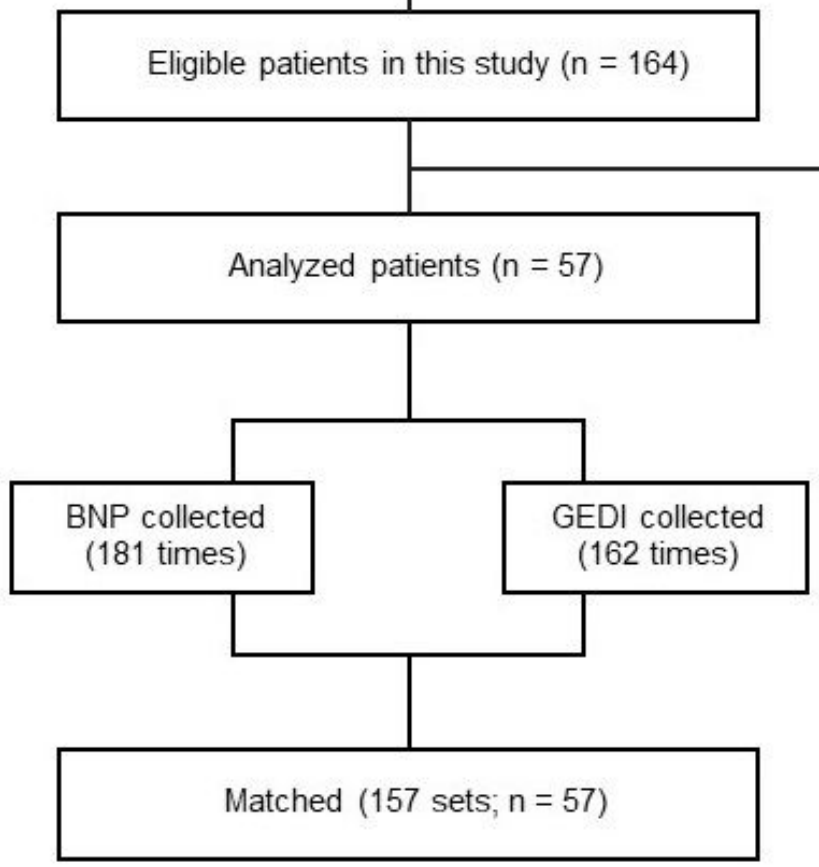

Excluded patients in this study $(n=107)$

Ischemic heart disease $(n=9)$

Chronic heart failure $(n=4)$

Cardiomyopathy $(n=3)$

Chronic kidney disease $(n=9)$

BNP not collected $(n=5)$

GEDI not collected $(n=86)$

Withdrew consent $(n=3)$

Duplicate registration $(n=1)$

\section{Figure 1}

Flow of patients screening and enrollment. Abbreviations: BNP, brain natriuretic peptide; CVP, central venous pressure; DNAR, do not resuscitate; ECMO, extracorporeal membrane oxygenation; GEDI, global end-diastolic volume; TPTD, transpulmonary thermodilution. 

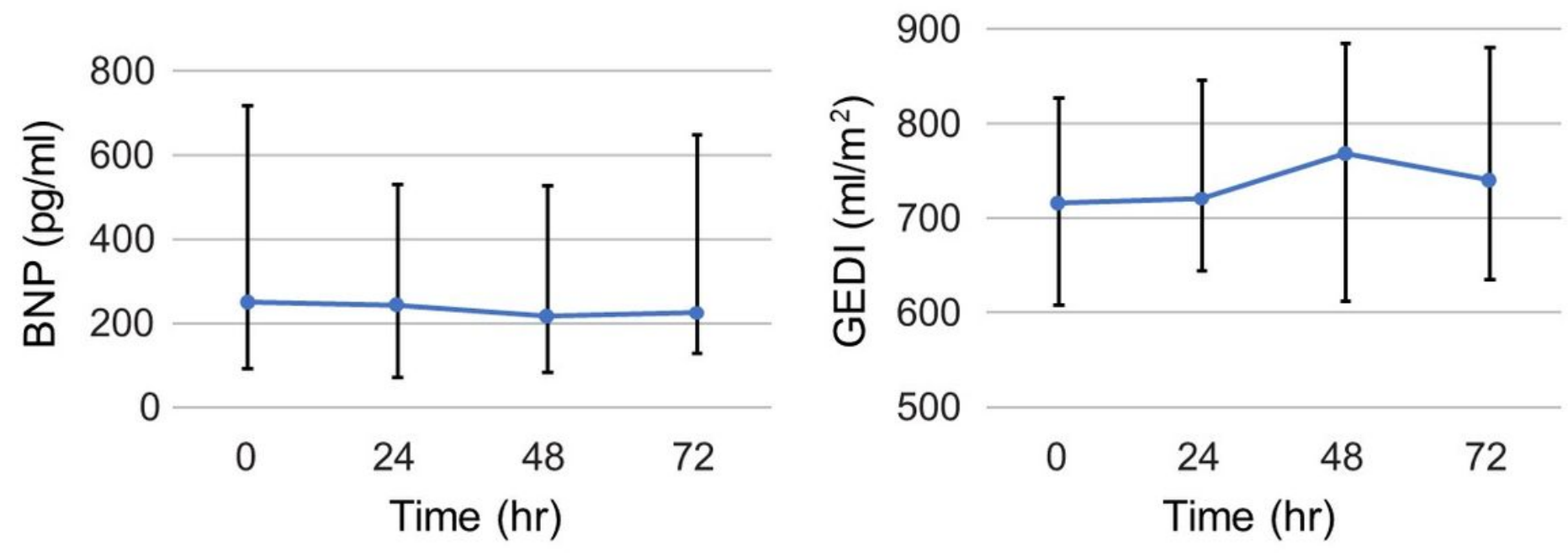

\begin{tabular}{|l|c|c|c|c|c|}
\hline & $0 \mathrm{hr}$ & $24 \mathrm{hr}$ & $48 \mathrm{hr}$ & $72 \mathrm{hr}$ & All times \\
\hline $\begin{array}{l}\text { BNP, pg/ml [median } \\
\text { value (IQR)] }\end{array}$ & $251(94-720)$ & $243(73-532)$ & $217(83-529)$ & $225(128-649)$ & $243(87-623)$ \\
\hline $\begin{array}{l}\text { GEDI, } \mathrm{ml} / \mathrm{m}^{2} \text { [median } \\
\text { value (IQR)] }\end{array}$ & $716(609-827)$ & $721(645-847)$ & $769(613-886)$ & $741(635-881)$ & $724(614-847)$ \\
\hline
\end{tabular}

Figure 2

Trends of BNP and GEDI over time. Abbreviations: BNP, brain natriuretic peptide; GEDI, global enddiastolic volume.

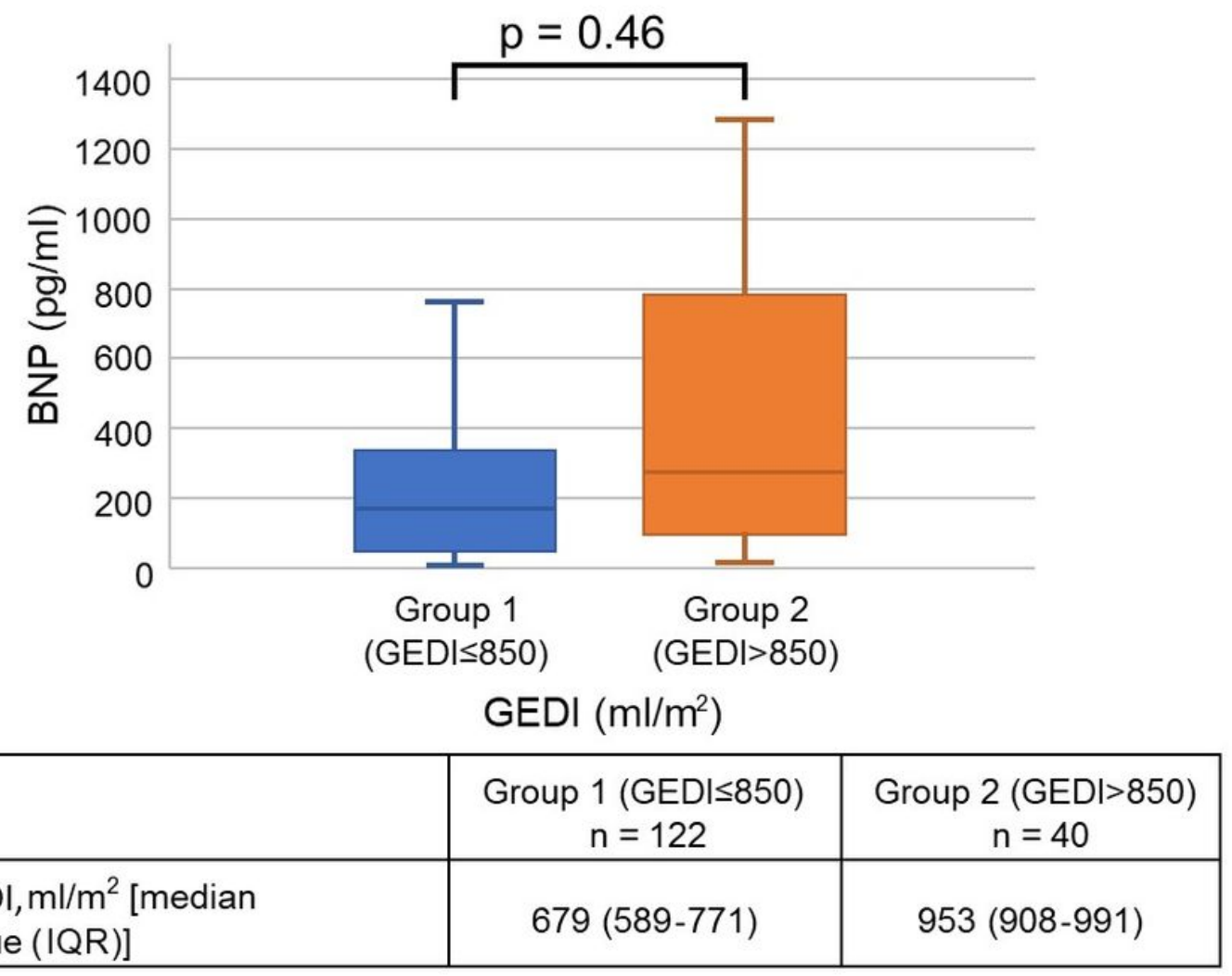




\section{Figure 3}

The median value of BNP at all times grouped by GEDI. A generalized linear mixed effects model in which patients are treated as a variable effect was used. Abbreviations: BNP, brain natriuretic peptide; GEDI, global end-diastolic volume. 